\title{
Análise temporal da ocorrência de focos de calor e uso e cobertura do solo no município de Marabá, Pará, Brasil
}

Temporal analysis of the occurrence of hot spots and land use and cover in the municipality of

Marabá, Pará, Brazil

Análisis temporal de la ocurrencia de puntos calientes y uso y cobertura del suelo en el municipio de Marabá, Pará, Brasil

\section{Resumo}

As intervenções antrópicas no meio ambiente são processos constantes e evolutivos. Desde os primórdios da humanidade o homem mudou o curso e a forma de interação com a natureza na luta pela sobrevivência, e entre as ferramentas de intervenção destacam-se, as queimadas e o desmatamento. Este estudo tem como objetivo analisar a dinâmica dos focos de calor e uso e cobertura do solo referente aos anos de 2010, 2012, 2014, 2015,2017 e 2019. Classificou-se essa ocorrência em cinco classes: muito baixo, baixo, médio, alto e muito alto. Os dados vetoriais foram obtidos das plataformas do Instituto de pesquisas espaciais - INPE e do projeto Mapbiomas da coleção 5. Para a elaboração dos mapas utilizou-se o Qgis 3.10.12 Corunã. Verificou-se que a classe Muito Baixo se manteve constante durante o período estudado, as classes Médio, Alto e Muito Alto se concentraram no centro e leste do município. A maior ocorrência dos focos de calor ocorreu nos meses de agosto a novembro com pico em outubro, isso em todos os anos. São apresentados resultados das análises de uso e cobertura do solo entre os anos de 2010 a 2019. Observa-se que as áreas ocupadas em 2010 crescem constantemente, na classe de área antropizadas em relação às outras classes corpo hídrico e vegetação. A classe vegetação apresentou-se uma perda de 10.675.143,29 ha de área, ao qual no ano 2010 evidencia-se $32,41 \%$, e em 2019 o valor percentual de área foi 30,07\%, representando uma perda total de 2,34\%. Os resultados demonstrados na presente pesquisa auxiliam na prevenção e no combate de incêndios florestais através de representação espacial e temporal que é extremamente útil nos planejamentos de combates de queimadas irregulares em Marabá.

Palavras-chave: Uso e cobertura do solo; Queimadas; Geotecnologias. 


\begin{abstract}
Anthropic interventions in the environment are constant and evolving processes. Since the dawn of humanity, man has changed the course and form of interaction with nature in the struggle for survival, and among the tools of intervention stand out, burning and deforestation. This study aims to analyze the dynamics of hotspots and land use and coverage referring to the years 2010, 2012, 2014, 2015, 2017 and 2019. This occurrence was classified into five classes: very low, low, medium, high, and very high. The vector data were obtained from the platforms of the Institute for Spatial Research - INPE and from the Mapbiomas project of collection 5. Qgis 3.10.12 Corunã was used for the elaboration of the maps. It was verified that the Very Low class remained constant during the studied period, the Medium, High and Very High classes were concentrated in the center and east of the municipality. The highest occurrence of hot spots occurred in the months of August to November, with a peak in October, in all years. Results of the analysis of land use and land cover between the years 2010 to 2019 are presented. It is observed that the occupied areas in 2010 grow constantly, in the anthropized area class in relation to the other classes water body and vegetation. The vegetation class presented a loss of 10,675,143.29 ha of area, which in the year 2010 evidences $32.41 \%$, and in 2019 the percentage value of area was $30.07 \%$, representing a total loss of $2.34 \%$. The results demonstrated in this research assist in the prevention and combat of forest fires through spatial and temporal representation that is extremely useful in the planning of combating irregular burning in Marabá.
\end{abstract}

Keywords: Land use and cover; Burning; Geotechnologies.

\title{
Resumen
}

Las intervenciones antrópicas en el medio ambiente son procesos constantes y evolutivos. Desde los albores de la humanidad, el hombre ha cambiado el rumbo y la forma de interacción con la naturaleza en la lucha por la supervivencia, y entre las herramientas de intervención destacan la quema y la deforestación. Este estudio tiene como objetivo analizar la dinámica de los puntos calientes y el uso del suelo y la cobertura para los años 2010, 2012, 2014, 2015,2017 y 2019. Esta ocurrencia se clasificó en cinco clases: muy baja, baja, media, alta y muy alta. Los datos vectoriales se obtuvieron de las plataformas del Instituto de Investigaciones Espaciales - INPE y del proyecto Mapbiomas de la colección 5. Para la elaboración de los mapas se utilizó Qgis 3.10.12 Corunã. Se verificó que la clase Muy Baja se mantuvo constante durante el período estudiado, las clases Media, Alta y Muy Alta se concentraron en el centro y este del municipio. La mayor aparición de puntos calientes se produjo en los meses de agosto a noviembre, con un pico en octubre, en todos los años. Se presentan los resultados del análisis del uso y la cobertura del suelo entre los años 2010 y 2019 . Se observa que las áreas ocupadas en 2010 crecen constantemente, en la clase de área antropizada en relación con las otras clases masa de agua y vegetación. La clase de vegetación presentó una pérdida de 10.675.143,29 ha de superficie, que en 2010 muestra un 32,41\%, y en 2019 el valor porcentual de superficie fue de 30,07\%, lo que representa una pérdida total de 2,34\%. Los resultados demostrados en esta investigación ayudan a la prevención y al combate de los incendios forestales a través de la representación espacial y temporal que es extremadamente útil en la planificación del combate a los incendios irregulares en Marabá.

Palabras clave: Uso y cobertura del suelo; Quema; Geotecnologías.

\section{Introdução}

As intervenções antrópicas no meio ambiente são processos constantes e evolutivos. A descoberta do fogo nos primórdios da humanidade alterou o curso e a forma de interação do homem com a natureza, na busca por recursos naturais, essas alterações estão associadas a conversão de florestas em áreas destinadas à produção agropastoril e a intensa exploração madeireira (Rosan et al., 2017; Castro 2019).

No Brasil, os incêndios florestais e queimadas são problemas antigos, provocados por processos antrópicos (expansão de áreas de ocupação, transformação de florestas em lavouras e/ou pastagens, controlar incidências de pragas, limpeza e etc.), e naturais (radiação) associados às estiagens mais intensas e frequentes que contribuem para o aumento da frequência desses eventos na Amazônia conforme (Medeiros \& Fieldler 2004, Aragão et al., 2007, Morton et al., 2008, Bowman et al., 2008, Cunha et al., $2007 \&$ Torres et al., 2017).

Esses eventos influenciam grandemente no clima e ecossistemas tropicais em decorrência da sua relação com as alterações no balanço de carbono, ciclo hidrológico, extinção de espécies, perda da biodiversidade, o aumento dos gases do efeito estufa, a destruição dos microrganismos e consequente perda da fertilidade do solo, provocando um desequilíbrio ecológico conforme (Hansen et al., 2004, Mesquita 2008, Granemann \& Carneiro 2009, Herawati \& Santos 2011, Caldas et al., 2014 e Lagoa \& Joaquim 2016). 
Os focos de calor são dados que registram temperaturas acima de $47{ }^{\circ} \mathrm{C}$ em escala pontual, diferente de incêndios florestais que por imagens de satélites esses avançam sobre grandes áreas, degradando a vegetação local (Pereira, 2019). Nesse contexto, o monitoramento dos focos de calor por meio do sensoriamento remoto e geoprocessamento, proporcionam uma análise multitemporal sobre sua distribuição espacial, permitindo estudar as interações do fogo com fatores culturais e socioambientais (Pereira et al., 2012).

Com isso, o presente estudo tem como objetivo realizar uma análise temporal dos focos de calor detectados em diferentes usos e cobertura da terra mapeados em 2010, 2012, 2014, 2015, 2017 e 2019 para o município de Marabá-PA, a fim de avaliar qual tipo de uso e cobertura estão relacionados às queimadas e seu padrão ao longo do tempo.

\section{Metodologia}

A área de estudo (Figura 1), compreende ao município de Marabá, Mesorregião Sudeste Paraense, com o par de

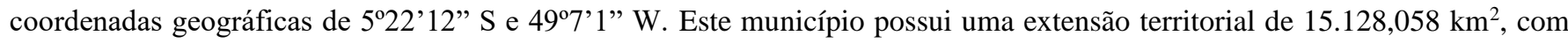
uma população de aproximadamente 283.542 habitantes segundo estimativas do Instituto Brasileiro de Geografia e Estatística (IBGE, 2021).

Figura 1 - Mapa de localização do município de Marabá - PA.

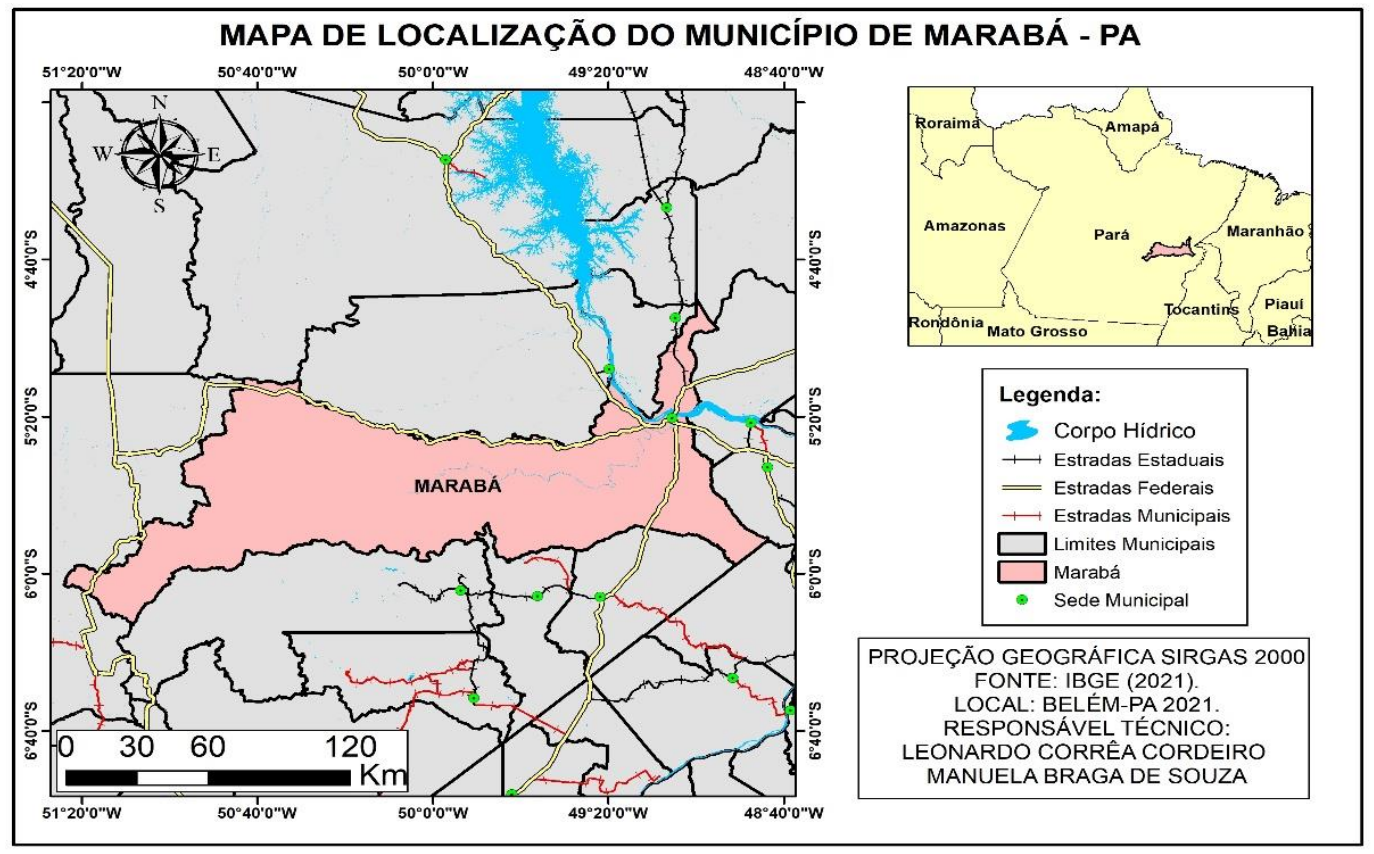

Fonte: Autores (2021).

O PIB per capita do município é de $\mathrm{R} \$ 31.920,20$ com 70,5\% do percentual de receitas oriundas de fontes externas. O clima do município é classificado como Tropical úmido com 9 meses de precipitação e 3 meses de seca (IBGE, 2021). Com uma temperatura média de $27,06^{\circ} \mathrm{C}$, com umidade relativa variando de $70,34 \%$ até $85,37 \%$ (INMET, 2020).

A vegetação predominante é de floresta ombrófila densa (floresta tropical fluvial), predominante na região amazônica e está ligada aos fatores do clima tropical de elevadas temperaturas e com precipitações bem distribuídas durante o ano (IBGE, 2019).

Para avaliar o desenvolvimento dos focos de calor no município de Marabá/PA foi utilizado banco de dados disponível do Instituto Nacional de Pesquisas Espaciais (INPE), realizou-se o download de focos de calor no formato vetorial (shapefile), 
além de planilha eletrônica em formato CSV para posteriormente serem trabalhados e tratados no software SIG Qgis e Excel respectivamente.

Para a elaboração dos mapas (limites territoriais, municipais) foram obtidos dados geoespaciais do banco de dados do Instituto Brasileiro de Geografia e Estatística (IBGE). Os dados referentes às variáveis uso e ocupação do solo foram obtidos da Coleção 5.0 do projeto Mapbiomas. O banco de dados permite acompanhar o desenvolvimento dos impactos ambientais no período de 2010 até 2019.

O processamento dos dados ocorreu no software SIG Qgis cuja versão é 3.10.12 Corunã. O shapefile de focos de calor e do município foram adicionados no software, os dados matriciais de densidade de focos de calor acumulados para cada período foram determinados pelo estimador de densidade de Kernel.

De acordo com Silverman (1986), o método kernel projeta uma vizinhança circular ao redor de cada ponto da amostra, correspondendo ao raio de influência, e então é aplicada uma função matemática de 1 , na posição do ponto, a 0 , ao redor da vizinhança. $\mathrm{O}$ valor para a célula é a soma dos valores kernel sobrepostos, e divididos pela área de cada raio de pesquisa.

Em seguida essas concentrações foram distribuídas em 5 classes: muito baixa, baixa, média, alta e muito alta. A utilização do algoritmo de densidade de Kernel permite obter uma estimação suavizada da densidade de eventos por unidade de área (Santos \& Assunção, 2003). Esta concentração de focos pode variar pela quantidade de focos, ou seja, quanto mais amostra de focos tiver em um shapefile maior será a densidade adquirida.

A execução dos dados de uso e cobertura do solo foram derivados através de recorte espacial das imagens do município de Marabá através da plataforma em nuvem Google Earth Engine (GEE). Foram trabalhados em um intervalo de 6 anos referente a 2010, 2012, 2013, 2015, 2017 e 2019 além de dados em planilha eletrônica fornecido pelo projeto Mapbiomas com valores em hectares de uso e cobertura do solo, onde foram adaptadas às classes do Mapbiomas para as seguintes classes: Área antropizadas, corpo hídrico e vegetação.

\section{Resultados e Discussão}

Os dados referentes aos focos de calor foram tabulados para análise, pode-se verificar os meses em que ocorreu a maior frequência dos focos detectados (Tabela 1).

Tabela 1 - Tabela referente a distribuição dos focos de calor de forma mensal entre os anos de 2010 e 2019 no município de Marabá/PA.

\begin{tabular}{l|cccccc}
\multicolumn{1}{c}{ Mês/Ano } & $\mathbf{2 0 1 0}$ & $\mathbf{2 0 1 2}$ & $\mathbf{2 0 1 3}$ & $\mathbf{2 0 1 5}$ & $\mathbf{2 0 1 7}$ & $\mathbf{2 0 1 9}$ \\
\hline Janeiro & - & - & 19 & 40 & 24 & 30 \\
Fevereiro & 1 & 7 & 9 & 2 & 1 & \\
Março & 1 & 5 & 1 & 2 & 3 & 3 \\
Abril & - & 5 & 2 & 1 & 2 & 12 \\
Maio & 3 & 11 & 5 & 5 & 8 & 9 \\
Junho & 9 & 27 & 12 & 42 & 83 & 159 \\
Julho & 203 & 119 & 58 & 117 & 625 & 747 \\
Agosto & 1.348 & 1.802 & 202 & 1.114 & 884 & 1.588 \\
Setembro & 2.569 & 3.551 & 733 & 3.557 & 6.567 & 2.748 \\
Outubro & 618 & 1.901 & 1.034 & 3.939 & 3.887 & 2.102 \\
Novembro & 108 & 281 & 96 & 982 & 407 & 1.021 \\
Dezembro & 15 & 22 & 190 & 372 & 184 & 286 \\
\hline
\end{tabular}

Fonte: Autores (2021). 
Os meses que apresentaram mais ocorrência de focos de calor foram agosto, setembro e outubro, para todos os anos do referido estudo. Os anos com maior destaque são 2015 e 2017, em 2015 foram 1.114 focos em agosto, 3.557 em setembro e 3.939 em outubro; em 2017 ocorreram 884 em agosto, $6.567 \mathrm{em}$ setembro e $3.887 \mathrm{em}$ outubro. De acordo com Jesus et al. (2020), o período de julho até novembro durante os anos de 2013 até 2017, apresentaram maior ocorrência de focos de calor e esse fenômeno mostrou-se correlação com os altos números de incêndios florestais em áreas desmatadas. O fator antrópico é importante para esse fenômeno, visto que durante os meses de outubro e novembro é feito no solo a limpeza de áreas destinadas a agricultura, através da utilização da queima (Cristóvão \& Rayol, 2021).

As densidades dos focos de calor obtidas pela metodologia de Densidade de Kernel, classificadas em Baixo, Muito baixo, Médio, Alto e Muito alto correspondem a diversas variações entre os meses de Agosto a Setembro, pois, na região Dias et al. (2018) comentam que durante esse período ocorre redução na precipitação pluviométrica e torna-se o clima ainda mais seco e com facilidade a proliferação de incêndios florestais no município (Figura 2).

Figura 2 - Classificação dos focos de calor por meio da metodologia de Densidade de Kernel do período de 2010 até 2019 no município de Marabá/PA.

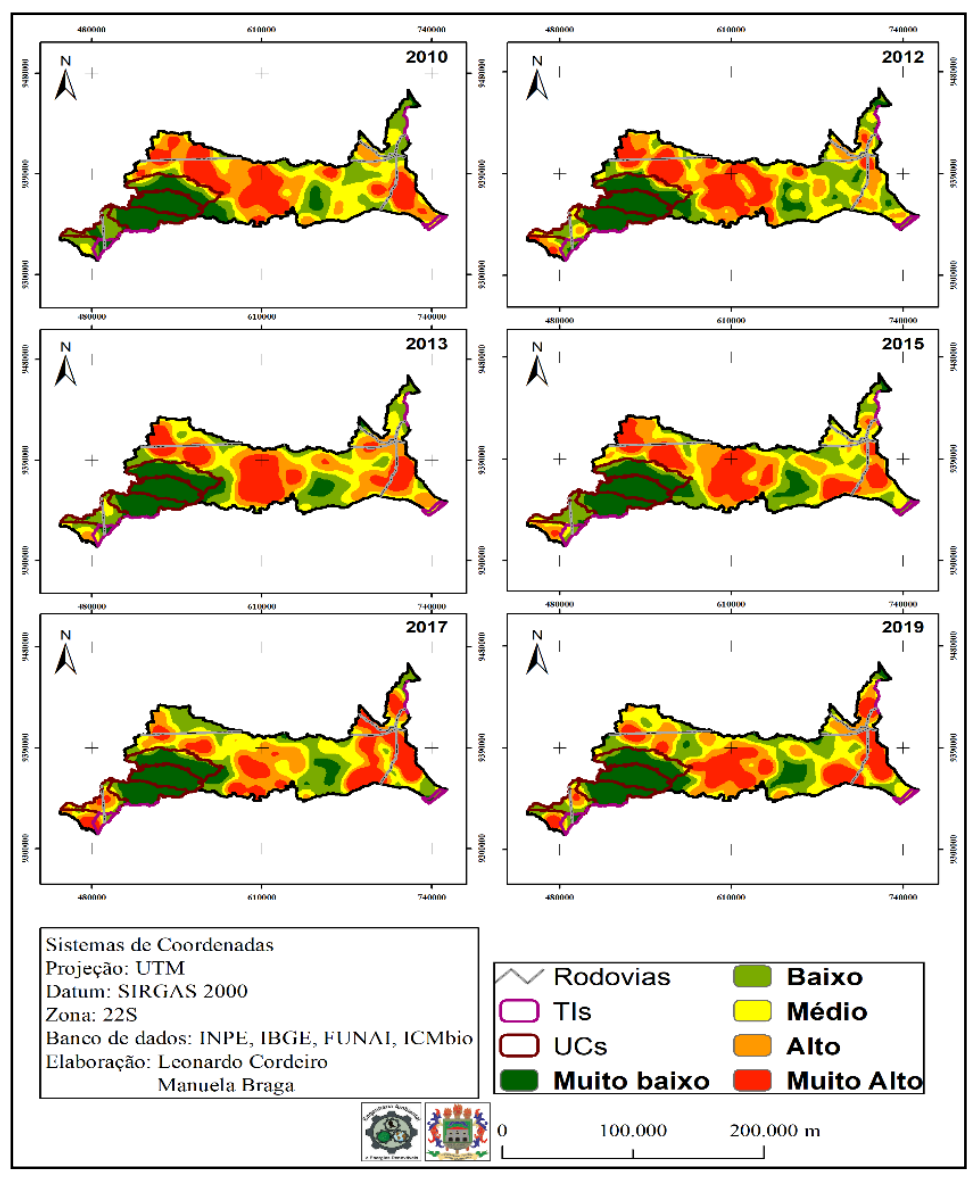

Fonte: Autores (2021).

No entanto, verifica-se que as classes Médio, Alto e Muito Alto cobrem grande parte do território do município. Essas classes concentram-se principalmente no centro e a leste do município. O ano de 2010 teve a classe Muito Alto com maior destaque, seguido do ano de 2012, embora os anos com maior número de focos de calor tenha sido 2015 e 2017. Nos anos de 2010, 2012 e 2015 os focos de queimadas apresentaram maior concentração espacial em regiões onde predominam as atividades 
de pecuária e agricultura. Nos anos de 2017 e 2019 as classes Médio, Alto e Muito Alto, mostraram predominância em áreas urbanas, com uma diminuição da classe Muito Alto no centro do município, no ano de 2017.

A Classe Muito baixo, referente a baixa distribuição de focos de calor, manteve-se constante durante o período analisado, 2010 até 2019. Na área correspondente a classe Muito Baixo, estão localizadas a Reserva Biológica do Tapirapé e FLONA do Tapirapé-Aquiri (IBGE, 2019).

Na Tabela 2, são apresentados resultados das análises de uso e cobertura do solo entre os anos de 2010 a 2019. Observase que as áreas ocupadas pelas classes de áreas antropizadas crescem constantemente ao longo tempo.

Tabela 2 - Valores em área (ha) e (\%) das classes de uso e cobertura do solo.

\begin{tabular}{|c|c|c|c|c|c|c|c|c|c|c|c|c|}
\hline \multirow{2}{*}{ Classes } & \multicolumn{2}{|c|}{2010} & \multicolumn{2}{|c|}{2012} & \multicolumn{2}{|c|}{2013} & \multicolumn{2}{|c|}{2015} & \multicolumn{2}{|c|}{2017} & \multicolumn{2}{|c|}{2019} \\
\hline & $\mathrm{Hec}$ & $\%$ & $\mathrm{Hec}$ & $\%$ & $\mathrm{Hec}$ & $\%$ & $\mathrm{Hec}$ & $\%$ & $\mathrm{Hec}$ & $\%$ & $\mathrm{Hec}$ & $\%$ \\
\hline Área & 1.523 .512 & 67,0 & 1.508 .567 & 66,7 & 1.545 .818 & 67,7 & 1.515 .021 & & 1.568 .523 & 68,4 & 1.602 .468 & 69,3 \\
\hline Antropizada &, 57 & 7 &, 14 & 0 &, 35 & 5 &, 03 & 66,85 &, 26 & 3 & ,97 & 9 \\
\hline $\begin{array}{l}\text { Corpo } \\
\text { Hídrico }\end{array}$ & $11.772,52$ & 0,52 & $10.095,06$ & 0,45 & $12.375,79$ & 0,54 & $12.816,47$ & 0,57 & $12.409,70$ & 0,54 & $12.374,02$ & 0,54 \\
\hline & $\begin{array}{c}736.113,6 \\
1\end{array}$ & $\begin{array}{c}32,4 \\
1\end{array}$ & $\begin{array}{c}743.166,0 \\
2\end{array}$ & $\begin{array}{c}32,8 \\
6\end{array}$ & $\begin{array}{c}723.558,2 \\
4\end{array}$ & 31,7 & $\begin{array}{c}738.350,9 \\
9\end{array}$ & 32,58 & $\begin{array}{c}711.203,2 \\
4\end{array}$ & $\begin{array}{c}31,0 \\
3\end{array}$ & 694.508,6 & $\begin{array}{c}30,0 \\
7\end{array}$ \\
\hline $\begin{array}{l}\text { Vegetação } \\
\text { Total }\end{array}$ & $\begin{array}{c}1 \\
2.271 .398\end{array}$ & $\begin{array}{c}1 \\
100\end{array}$ & & $\begin{array}{c}0 \\
100\end{array}$ & & $\begin{array}{c}1 \\
100\end{array}$ & & & & 100 & 2309351 & \\
\hline $\begin{array}{l}\text { Total } \\
\text { Geral }\end{array}$ & $\begin{array}{c}2.271 .398 \\
, 70\end{array}$ & $\begin{array}{c}100, \\
00\end{array}$ & $\begin{array}{c}2.261 .828 \\
, 22\end{array}$ & $\begin{array}{c}100, \\
00\end{array}$ & $\begin{array}{c}2.281 .752 \\
, 38\end{array}$ & $\begin{array}{c}100, \\
00\end{array}$ & $\begin{array}{c}2.266 .188 \\
, 49\end{array}$ & $\begin{array}{c}100,0 \\
0\end{array}$ & $\begin{array}{c}2.292 .136 \\
, 20\end{array}$ & $\begin{array}{c}100, \\
00\end{array}$ & $\begin{array}{c}2.309 .351 \\
, 61\end{array}$ & $\begin{array}{c}100, \\
00\end{array}$ \\
\hline
\end{tabular}

Fonte: Autores (2021).

Por conseguinte, a classe vegetação apresentou-se uma perda de 10.675.143,29 ha de área, ao qual no ano 2010 evidencia-se 32,41\%, e em 2019 o valor percentual de área foi 30,07\%, representando uma perda total de 2,34\%.

Nessa lógica Sousa et al. (2017) afirma que a observação entre as transições sobre os respectivos anos, é uma dinâmica acelerada sobre as modificações da cobertura vegetal, com uma redução progressiva na classe vegetação e do corpo hídrico e o avanço das áreas antropizadas.

Em decorrência das alterações das atividades antropizadas que ocorreram em Marabá, advindo da agricultura e da pecuária com as áreas de pastagens, no qual apresenta-se 67,07\% na transição de uso e cobertura do solo em 2010, e em 2019 o valor percentual da área foi de $69,39 \%$ representando um aumento total de $2,32 \%$.

Os dados mostram que apesar do avanço da pecuária ser uma das atividades dessa mesorregião, Carvalho (2017), corrobora ainda que a intensificação da urbanização é um dos fatores que impactada diversos núcleos em Marabá.

De acordo com Pereira Júnior et al. (2020) as análises das alterações no município de Marabá apresentam-se a maior área devastada logo no primeiro triênio. A classe de áreas antropizadas, possui, no entanto, o maior índice de área desflorestada no município sudeste do Pará, enquanto as demais classes reduziu-se, tornando-se preocupante o cenário no contexto ambiental.

A partir dos mapas de evolução temporal figura 3, é possível observar diversas alterações espaciais nos processos de mudanças no uso e cobertura do solo. Para Carvalho (2017), a análise temporal é um importante instrumento para a verificação sobre as alterações que impactam diretamente na superfície da terra. 
Figura 3 - Classificação de uso e cobertura do solo entre os períodos de 2010 até 2019.

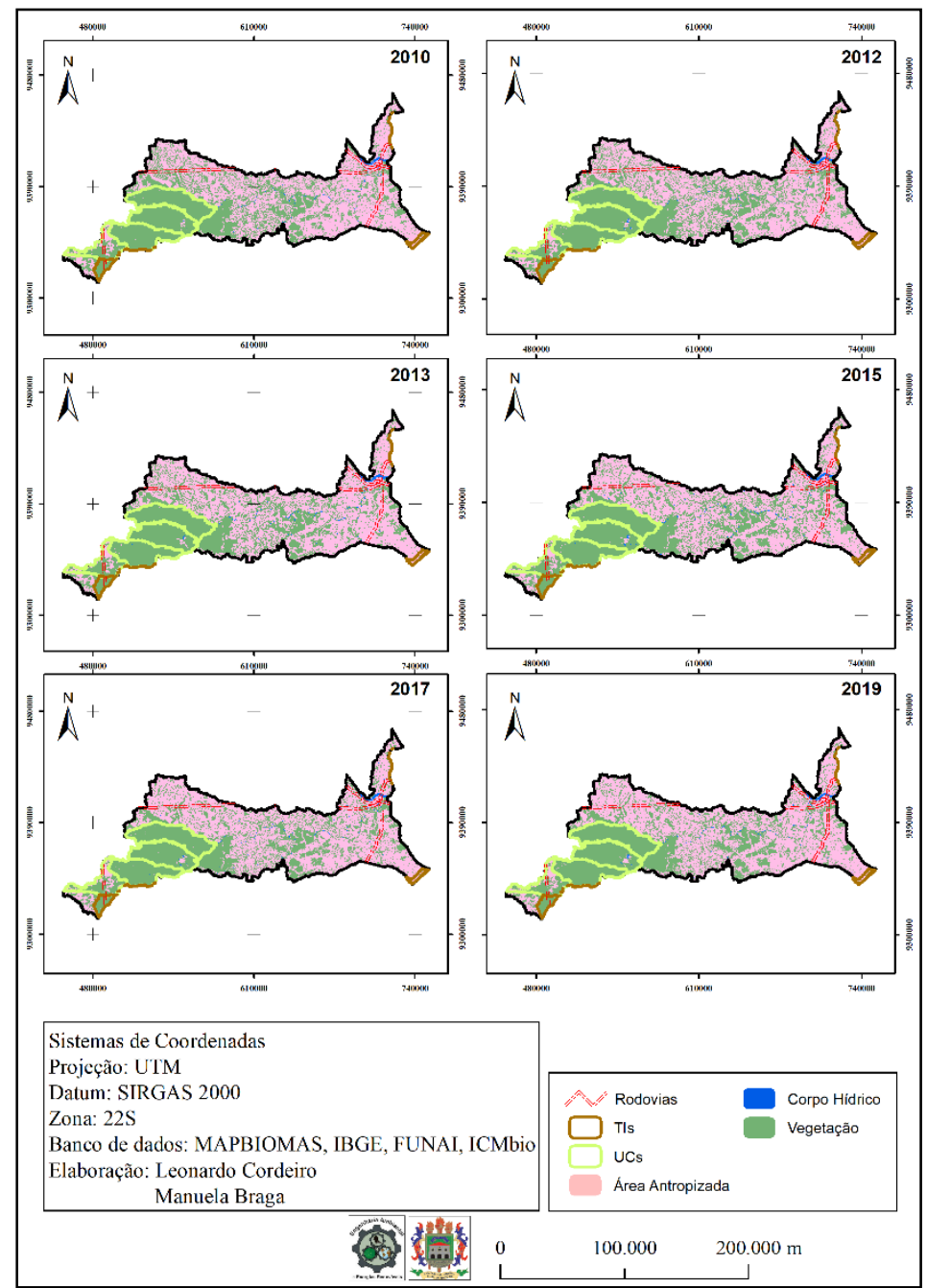

Fonte: Autores (2021).

Ao avaliar a evolução temporal, é perceptível visualizar os processos de expansão no município de Marabá, desde então a supressão da vegetação é intensamente reduzida em análise comparativa entre os anos de 2010 a 2019.

Nessa lógica, Bitencourt, Reis e Loureiro (2020), diz que Marabá é destaque em pecuária na região da integração do Carajás, no qual configura-se o município como o segundo maior efetivo bovino da região. O aumento do desmatamento com a substituição por pastagens sem planejamento apropriado são causas prejudiciais ao ambiente e precisa-se de monitoramento mais rígido e eficaz diante da realidade que Marabá vem sendo submetida.

\section{Conclusão}

O estudo aborda um aumento significativo de focos de calor entre os meses de agosto, com pico alarmante em outubro e redução em novembro, esse fenômeno é observado em todos os anos de estudo. Pode-se concluir que boa parte das queimadas são concentradas com destaque no centro do município, ocasionando impactos ambientais que afetam tanto a população da região quanto a biodiversidade local.

Os resultados demonstrados na presente pesquisa auxiliam na prevenção e no combate de incêndios florestais através de representação espacial e temporal que é extremamente útil nos planejamentos de combates de queimadas irregulares em 
Marabá. O uso e cobertura do solo e as dinâmicas ambientais, necessitam de ações mitigadoras com a afinidade de reduzir os impactos ambientais decorrente do crescimento populacional e das atividades econômicas.

As ferramentas geotecnológicas são fundamentais e importantes para detecção e monitoramento de desmatamento e focos de calor (queimadas), pois tais informações são essenciais para o delineamento de políticas públicas na região. Dessa forma, baseada nas ideias expostas, o presente trabalho espera ter repassado uma leitura de fácil compreensão e de qualidade, entre a dinâmica dos focos de queimadas em contrapartida ao uso e cobertura do solo.

\section{Referências}

Aragão, L. E. et al. (2007). Spatial patterns and fire response of recent Amazonian droughts. Geophysical Research Letters, 34(7).

Bitencourt, E. B. E., dos Reis, L. M., \& Loureiro, G. E. (2020). Análise Temporal do Desmatamento na Bacia Hidrográfica do Rio Sororó - Região de Integração de Carajás, PA. Revista Geoaraguaia, v. 10(1), 89-106.

Bowman, D. M. J. S., Amacher, G. S., \& Merry, F. D. (2008). Fire use and prevention by traditional households in the Brazilian Amazon. Ecological Economics, 67(1), 117-130.

BRASIL. (2016). Atlas do desenvolvimento humano no Brasil 2013.

Caldas, M., Silva, F. B., \& Silva Junior, C. H. L. (2014). Análise de focos de queimadas no Parque Estadual do Mirador utilizando um Sistema de Informação Geográfica-SIG, Estado do Maranhão, Brasil. In: Proceedings of Safety, Health and Environment World Congress, $134-138$.

Carvalho, R. S. (2019). Análise Temporal da Cobertura $\quad$ Vegetal Urbano de Marabá/PA de 2006 a 2016. In: XVI Simpurb - Simpósio Nacional de Geografia Urbana, Vitoria, $3790-3809$.

Cristovão, E. E. M., \& Rayol, B. P. (2021). Análise espaço-temporal de focos de calor no município de São Francisco do Pará, nordeste paraense. Acta Tecnológica, 15(2), 69-79.

Cunha, A. M. C., Lima, C. A., \& Dietzsch, L. (2007). Levantamento de áreas de maior risco de incêndios através de dados NOAA12. Estudo de caso: Reserva Biológica do Guaporé. In: Anais XIII Simpósio Brasileiro de Sensoriamento Remoto, 4439 - 4446.

Dias, L. B. A. et al. (2020). Análise do risco de queimadas com uso do mapa de kernel no municipio de Marabá-PA. Org. Maria Elanny Damasceno Silva. Meio Ambiente, Recursos Hídricos e Saneamento Ambiental 2. Ponta Grossa, PR: Atena Editora.

Gil, A. C. (2010). Como Elaborar Projetos de Pesquisa. (5a ed.), Atlas.

Granemann, D. C., \& Carneiro, G. L. (2009). Monitoramento de focos de incêndio e áreas queimadas com a utilização de imagens de sensoriamento remoto. Revista de Engenharia e Tecnologia. 1(1)

Hansen, A. J., Defries., R \& Turner, W. (2004). Land Use Change and Biodiversity, 277-299.

Herawati, H., \& Santos, O. H. (2011). Tropical forest susceptibility to and risk of fire under changing climate: a review of fire nature, policy and institutions in Indonesia. Forest Policy and Economics, 13(4), 227-233. 10.1016/j.forpol.2011.02.006.

IBGE. (2002). Instituto Brasileiro de Geografia e Estatística. Portal de Mapas IBGE. 27 fev. 2021.

IBGE. (2019). Instituto Brasileiro de Geografia e Estatística. Províncias estruturais, compartimentos de relevo, tipos de solos, regiões fitoecológicas e outras áreas. IBGE, 1, 1-177.

IBGE. (2021). Instituto Brasileiro de Geografia e Estatísticas. Cidades. http:// IBGE | Cidades@ | Pará | Marabá | Panorama >.

INMTE. (2021). Instituto Nacional de Meteorologia. Dados Meteorológicos. https://bdmep.inmet.gov.br/.

Jesus, J. B. et al. (2020). Análise da incidência temporal, espacial e de tendência de fogo nos biomas e unidades de conservação do Brasil. Ciência Florestal, 30(1), 176-191.

Lagoa, R., \& Rodrigues, J. R. (2016). Biodiversidade, as Biotecnologias e a procura de uma nova Bioeconomia. Guia pedagógico da Floresta, 7-18.

Margulis, S. (2003). Causas do desmatamento da Amazônia Brasileira. Banco Mundial.

Medeiros, M.B., \& Fiedler N. C. (2004). Incêndios florestais no Parque Nacional da Serra da Canastra: Desafios para a conservação da biodiversidade. Ciência Florestal, 14(2): 157-168.

Mesquita, A. G. G (2008). Impactos das queimadas sobre o ambiente e a biodiversidade Acreana. Revista Ramal de Ideias, 1(1).

Morton, D. C., Defries, R. S., Randerson, J. T., Giglio, L., Schroeder, W., \& Van Der Werf, G. R. (2008). Agricultural intensification increases deforestation fire activity in Amazonia. Global Change Biology, 14(10), 2262- 2275.

Pereira, A. (2021). Entenda as diferenças entre queimadas, incêndios florestais e focos de calor. Governo de Mato Grosso. http://www.mt.gov.br/-/12486299entenda-as-diferencas-entre-queimadas-incendios-florestais-e-focos-de-calor. 
Research, Society and Development, v. 11, n. 1, e49011125198, 2022

(CC BY 4.0) | ISSN 2525-3409 | DOI: http://dx.doi.org/10.33448/rsd-v11i1.25198

Pereira Júnior, A., Pereira, L. C., Dias, L. B. A., \& Garcia, P. S. (2020). Análise Multitemporal do desmatamento ocorrido entre 2006 e 2017 no Sudeste do Pará. Gesta, 8(2), 102-109.

Pereira, A. A.; Pereira, J. A. A.; Morelli, F.; Barros, D. A.; Acerbi Júnior, F. W.; \& Scolforo, J. R. S. (2012). Validação de focos de calor utilizados no monitoramento orbital de queimadas por meio de imagens TM. Cerne, 18, 335-343.

Richardson, R. J. (2008). Pesquisa Social: Métodos e Técnicas. (3a ed.), Atlas.

Rosan, T. M., Anderson, L. O., \& Vedovato, L. (2017). Avaliação da Origem de Focos de Calor em Anos de Extremos Climáticos na Amazônia Brasileira. Revista Brasileira de Cartografia, 69(4).

Santos, A. A. C., \& Assunção, R. M. (2003). Um novo algoritmo para estimação de intensidade de processos pontuais. Revista Eletrônica de Iniciação Científica, $3(4), 385-413$.

Silva, M. V. S., da Silva, B. C. S., \& Lima, I. F. (2020). Análise da vulnerabilidade ambiental do município São João da Ponta, Pará: o uso do geoprocessamento na gestão de unidades de conservação. Revista Cerrados, 18(01), 159-188.

Sousa, L. M., Adami, M., Lima, A. M. M., \& Ramos, W. F. (2017). Avaliação do Uso e Cobertura da Terra em Paragominas e Ulianópolis-PA, utilizando dados do Projeto TerraClass. Revista Brasileira de Cartografia, 69(3), 421-431.

Souza, M. B., do Nascimento, R. E. N., Dias, G. F. M., \& Moreira, F. S. A. (2020). Dinâmica de uso e cobertura da terra no municipio de São Félix do Xingu, Estado do Pará, Brasil. Research, Society and Development, 9(10), 1-13.

Torres, F. T. P., Roque, M. P. B., Lima, G. S., Martins, S. V. \& de Faria, A. L. L. (2017). Mapeamento do risco de incêndios florestais utilizando técnicas de geoprocessamento. Floresta e Ambiente, 24. 